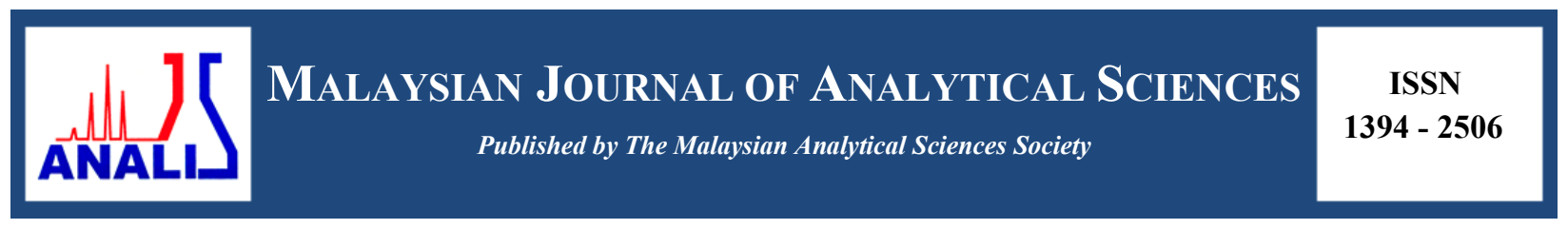

\title{
CHEMICAL SENSOR FOR HYDRAZINE DETECTION USING POLYANILINE THIN FILM
}

\author{
(Sensor Kimia Untuk Mengesan Hidrazin Dengan Menggunakan Polyanilina \\ Berbentuk Filem Nipis) \\ Kavirajaa Pandian Sambasevam ${ }^{1}$, Sharifah Mohamad ${ }^{2}$, Sook-Wai Phang ${ }^{3 *}$ \\ ${ }^{I}$ School of Chemistry and Environment, Faculty of Applied Sciences, \\ Universiti Teknologi MARA, Negeri Sembilan Branch,Kuala Pilah Campus, 72000 Kuala Pilah, Negeri Sembilan, Malaysia \\ ${ }^{2}$ Department of Chemistry, Faculty of Science, \\ University of Malaya, 50603 Kuala Lumpur, Malaysia \\ ${ }^{3}$ Department of Physical Science, Faculty of Applied Sciences, \\ Tunku Abdul Rahman University College, 53300 Kuala Lumpur, Malaysia \\ *Corresponding author: pinkyphang@gmail.com
}

Received: 17 August 2016; Accepted: 15 June 2017

\begin{abstract}
Polyaniline (PANI) doped with dioctyl sodium sulfosuccinate (AOT) was prepared by chemical oxidative polymerization method. This PANI thin film was used as an effective chemical sensor at room temperature for different concentrations of hydrazine $(10,100,1000$ and $10000 \mathrm{ppm})$ detection. The PANI chemical sensor has shown a good recyclability up to 10 cycles with 2 minutes response time and immediate recovery time. The sensor response was proved by red-shift of the UV-Vis at 780 $\mathrm{nm}$ which indicates the transformation of emeraldine salt (ES, conducting state) to leucoemeraldine salt (LES, non-conducting state) of PANI. Besides that, the intensity ratio of $I_{\text {Quinoid }} / I_{\text {Benzenoid }}$ at FTIR spectroscopy can explicit the predominating benzenoid species that formed as a result of ES interaction with hydrazine. In this study, a very simple and inexpensive sensor setup has been successfully developed for hydrazine detection compare to the complicated traditional chemical sensors.
\end{abstract}

Keywords: polyaniline, hydrazine, dioctyl sodium sulfosuccinate, chemical sensor, conductivity

\section{Abstrak}

Polianilina (PANI) yang didopkan dengan natrium dioktil sulfosuksinat (AOT) telah disediakan melalui kaedah pempolimeran pengoksidaan kimia. Filem nipis PANI telah digunakan sebagai sensor kimia pada suhu bilik untuk mengesan hidrazin dengan kepekatan yang berbeza (10, 100, 1000 dan 10000 ppm). Sensor kimia PANI telah menunjukkan penggunaan semula sehingga 10 kali dengan masa 2 minit dengan masa pemulihan segera. Keputusan sensor telah dibuktikan dengan peralihan-merah UV-Vis pada $780 \mathrm{~nm}$ yang menunjukkan transformasi garam emeraldina (ES, konduktif) kepada garam leukoemeraldina (LES, tidak konduktif). Selain itu, nisbah keamatan $\mathrm{I}_{\text {Kuinoid }} / \mathrm{I}_{\text {Benzenoid }}$ di FTIR spektroskopi telah menjelaskan spesies benzenoid lebih banyak sebagai hasil interaksi ES dengan hidrazin. Dalam kajian ini, penyediaan sensor yang sangat mudah dan murah telah berjaya diperkembangkan untuk mengesan hidrazin berbanding dengan sensor kimia tradisional yang rumit.

Kata kunci: polianilina, hidrazin, natrium dioktil sulfosuksinat, sensor kimia, konduktiviti

\section{Introduction}

In recent years, there has been growing interest in conducting polymers due to their versatile applications in light emitting diodes, electronic devices, sensors, actuators, catalysis, corrosion protection coatings and microwave 
absorption [1-5]. Among the conducting polymers, polyaniline (PANI) is the most promising semiconductor because of its ease of synthesis [6], high conductivity, low cost and good environmental stability [7, 8]. However, the great potential of PANI was masked by few disadvantages such as insolubility, infusibility and hence poor process ability. Attempts have been made to improve its solubility, of which the most widely used strategy is to dope PANI with suitable surfactants such as dodecylbenzene sulphonic acid (DBSA), camphor sulphonic acid (CSA) and etc. [9]. The PANI with improved solubility can be spin coated on an appropriate substrate to be used as a sensing material for toxic compounds such as ammonia, hydrogen peroxide, hydrazine and etc [10].

Hydrazine and its derivatives are commonly known for fuels in explosives, antioxidants, rocket propellants, blowing agents, photographic chemical, corrosion inhibitor, insecticides and plant growth regulators [11]. In spite of this, hydrazines are well known as neurotoxin, carcinogen, mutagen and hepatoxic [12]. Besides that, the exposure of high level of hydrazine can cause irritation to nose, eye, throat, dizziness, nausea, temporary blindness, pulmonary edema and coma, which will eventually endanger the liver, kidneys and central nervous system of humans [13].

Therefore, it has been realized that, effective and sensitive sensing methods need to be explored to detect the hydrazine. Presently, several efforts have been developed towards the rapid, sensitive and selective methods for the detection of hydrazine. The sensing properties of hydrazine have been extensively studied by various methods using different metal oxides, electrodes and semiconductors [14, 15]. Electroanalytical techniques were proven to be relatively direct and effective for the detection of hydrazine [16]. Unfortunately, hydrazine exhibits irreversible oxidation which required large overpotentials at bare carbon electrodes. Recently, various chemically modified electrodes (CMEs) have been prepared and applied in the detection of hydrazine [17-21], which can significantly lower the overpotentials and increase the oxidation current response. However, the tedious preparation method, expensive electrode modification techniques, control on $\mathrm{pH}$ of reactants have made these methods cumbersome and thus the door for a fast track, cheap and sensitive methodology is still opened. The preference for a conducting polymer especially PANI over a conventional metal as sensing material stems from several factors such as it can be operated at lower applied voltages and temperatures, unique acid-base chemistry and it interacts more favorably with both organic and inorganic compounds [10].

In this study, PANI was prepared by chemical oxidation method in the presence of dioctyl sodium sulfosuccinate (AOT) as a dopant to improve the solubility and enhance electrical conductivity. A very simple sensor set-up has been utilized and investigated by using UV-Vis, FTIR and conductivity studies to evaluate the response of PANI thin films against different concentrations of hydrazine such as 10,100,1000 and $10000 \mathrm{ppm}$.

\section{Raw materials}

\section{Materials and Methods}

All chemicals such as aniline (Ani) monomer, dioctyl sodium sulfosuccinate (AOT) and ammonium peroxydisulfate (APS) were purchased from Sigma Aldrich. Hydrochloric acid (HCl) 37\% was purchased from Lab Scan Sdn. Bhd. Technical grade of toluene was used as a solvent for PANI thin film preparation. Distilled water was used throughout the research. Other reagents were used without purification unless noted.

\section{Synthesis of PANI}

PANI was synthesized by chemical oxidation method at $0-5{ }^{\circ} \mathrm{C}$. Firstly, $1 \mathrm{mmol}$ of AOT was dissolved in $1 \mathrm{~N}$ of $\mathrm{HCl}$ followed by the dropwise addition of Ani $(1 \mathrm{mmol})$. Then, $1 \mathrm{mmol}$ of APS solution was added slowly into the solution mixture and the polymerization was preceded for 24 hours. After that, the PANI was washed by distilled water for three times and dispersed in toluene for film preparation by using spin coater.

\section{Characterizations}

The characterizations of PANI films were investigated through ultraviolet-visible (UV-Vis) by using UV-1650 PC spectrometer in the wavelength range of $300-900 \mathrm{~nm}$ and Fourier transform infrared (FTIR) by using Perkin Elmer RX1 FTIR ATR spectrometer in the range of $4000-400 \mathrm{~cm}^{-1}$. 


\section{Sensor set-up}

In this study, a simple and cost-effective sensor set-up has been developed by using glass cuvettes. PANI film was immersed into the hydrazine solution in cuvette to determine the response of PANI against hydrazine. Measurements were taken before and after immersion into hydrazine solution using UV-Vis and FTIR spectroscopy and standard four point probe method (model Loresta HP) was used to study the normalized conductivity.

\section{Characterizations}

\section{Results and Discussion}

UV-Vis spectrum of PANI was shown in Figure 1. The spectrum shows typical characteristic peaks of doped PANI such as $\pi-\pi^{*}$ conjugation at $350 \mathrm{~nm}$, shoulder peak at $415 \mathrm{~nm}$ which showed enhanced polaronic character and a peak at $779 \mathrm{~nm}$ that resembles doped state of quinoid cations [22].

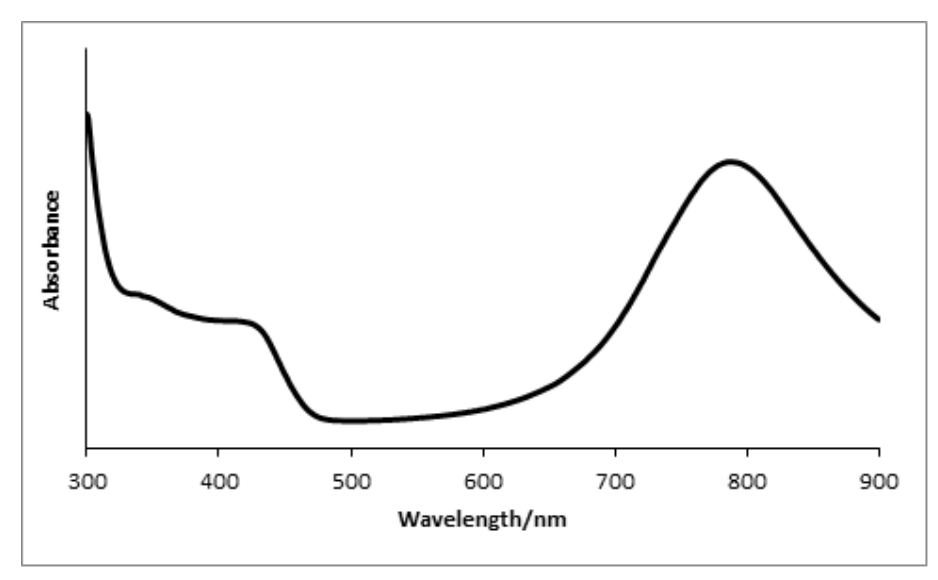

Figure 1. UV-Vis spectrum of doped PANI

The FTIR spectrum of PANI as shown in Figure 2 exhibited few significant peaks at $773 \mathrm{~cm}^{-1}$ which corresponds to the $\mathrm{C}-\mathrm{H}$ bending vibration out of the plane of benzene and $1140 \mathrm{~cm}^{-1}$ which attributed to the $\mathrm{NH}^{+}$vibration mode. Meanwhile, $1183 \mathrm{~cm}^{-1}$ peak shows the presence of $\mathrm{S}=\mathrm{O}$ symmetric and $1284 \mathrm{~cm}^{-1}$ peak shows asymmetric which arise from AOT dopant and C-N stretching peaks. The structure of PANI was confirmed by the appearance of main characteristic peaks at $1477 \mathrm{~cm}^{-1}$ and $1578 \mathrm{~cm}^{-1}$. These two peaks contributed to the stretching vibration mode of benzenoid ring and vibration mode of quinoid, respectively [23, 24]. Therefore, UV-Vis and FTIR spectra have confirmed the chemical structure of the resulted PANI.

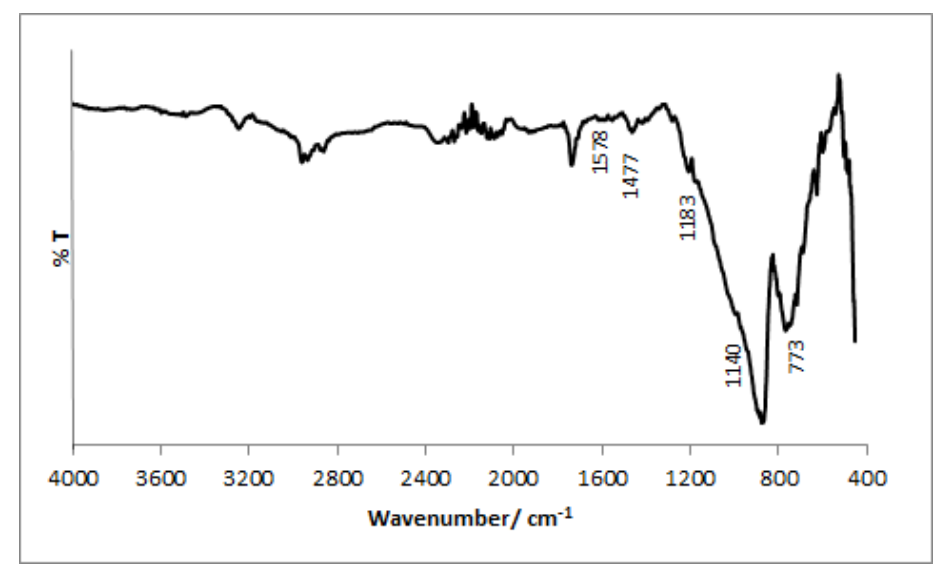

Figure 2. FTIR spectrum of doped PANI 


\section{Sensor measurements}

First of all, the immersion time for PANI into hydrazine was optimized through conductivity study. Figure 3 shows the effect of immersion time for PANI chemical sensor against $100 \mathrm{ppm}$ of hydrazine. The $y$-axis is the normalized conductivity $\left(\sigma_{\mathrm{f}} / \sigma_{\mathrm{i}}\right)$, where $\sigma_{\mathrm{i}}$ is the initial conductivity of the doped PANI (before immersion) and $\sigma_{\mathrm{f}}$ is the time dependent conductivity of the film after exposed to hydrazine. The PANI thin film has recorded an initial conductivity of $4.883 \times 10^{-2} \mathrm{~S} / \mathrm{cm}$ and it decreased with time after expose to $100 \mathrm{ppm}$ of hydrazine. After 2 minutes of exposure time, the conductivity of PANI film decreased to $2.133 \times 10^{-2} \mathrm{~S} / \mathrm{cm}$. Besides that, the normalized conductivity decreased insignificantly from the $2^{\text {nd }}$ minute to $5^{\text {th }}$ minute. Therefore, 2 minute was chosen as optimum exposure time of PANI for $100 \mathrm{ppm}$ of hydrazine. PANI exhibits decrease in overall conductivity upon exposure to hydrazine is due to the transformation of conducting state of PANI (emeraldine salt (ES)) to nonconducting state of PANI (leucoemeraldine salt (LES)) [25].

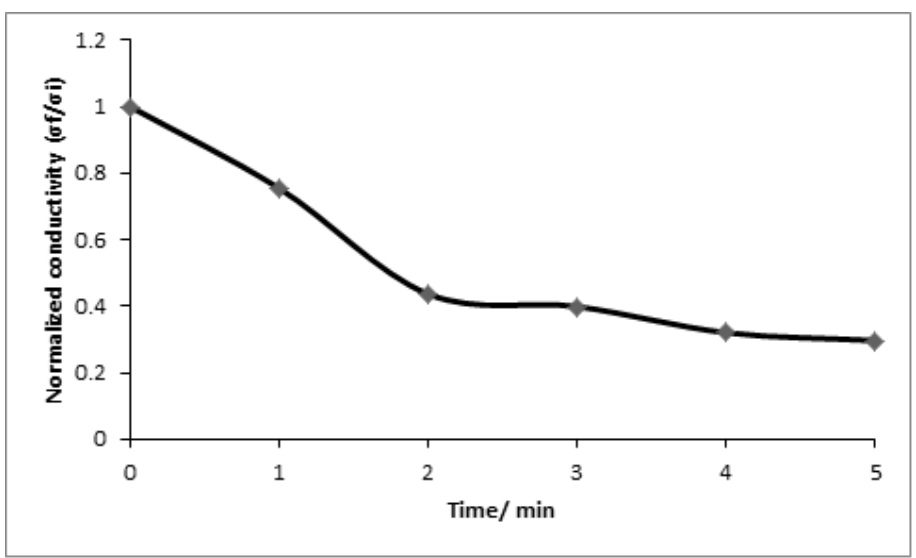

Figure 3. Normalized conductivity of PANI chemical sensor against $100 \mathrm{ppm}$ of hydrazine with respect to time

Figure 4 shows the response of PANI chemical sensor in term of conductivity study against different concentrations of hydrazine such as 10,100,1000 and $10000 \mathrm{ppm}$. The PANI thin films have recorded 2 minutes of response time for $10-100 \mathrm{ppm}$ of hydrazine while it showed an immediate response for $1000-10000 \mathrm{ppm}$ of hydrazine concentrations. It revealed that the decrease in conductivity for higher concentration of hydrazine is much bigger with shorter response time compare to the lower concentration of hydrazine. It is because of higher concentration of hydrazine will possess higher hydrazinium ions which can dedope the PANI from ES to LES at much faster rate and thus decrease the conductivity of the ES within a shorter response time [18].

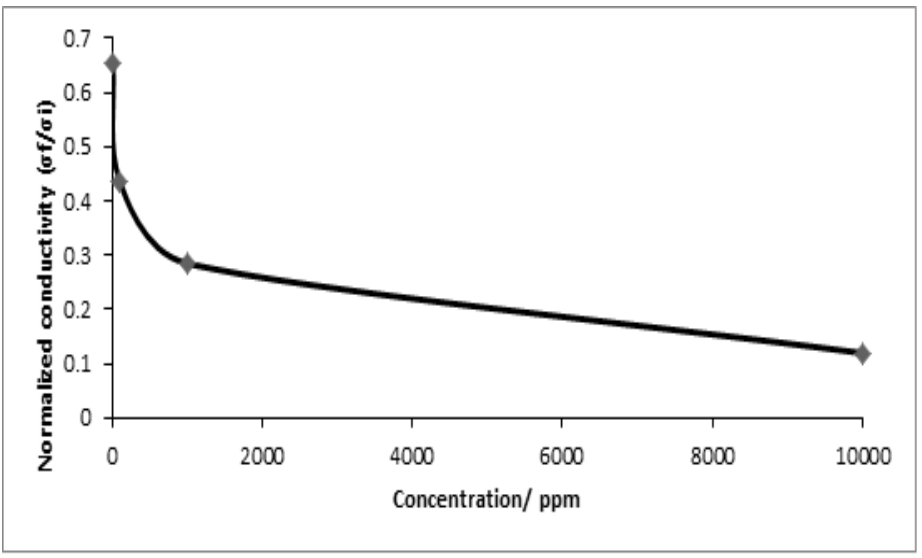

Figure 4. Normalized conductivity of PANI chemical sensor against different concentration of hydrazine 
On the other hand, the recyclability of PANI chemical sensor has also been evaluated via conductivity study. According to the theory, conducting state of PANI ES will possess benzenoids and quinoids that can be dedoped by hydrazine to form LES which is an electrical insulator with predominating benzenoid units. Later, LES can be redoped back by an acid to produce ES. Thus, it is known as a reversible interaction between ES and LES with the help of a reducing agent (hydrazine) and acid. Figure 5 shows that the PANI chemical sensor can be recycled up to 10 cycles. The initial conductivity of this film was $3.899 \times 10^{-2} \mathrm{~S} / \mathrm{cm}$ and the conductivity after the $10^{\text {th }}$ recycle was $6.167 \times 10^{-1} \mathrm{~S} / \mathrm{cm}$ [26]. It is observed that, the normalized conductivity of PANI chemical sensor is about 15 times higher compare to the initial conductivity. It is due to the role played by the acids that used to redope PANI chemical sensor. Normally, inorganic acids will yield PANI with higher conductivity [26].

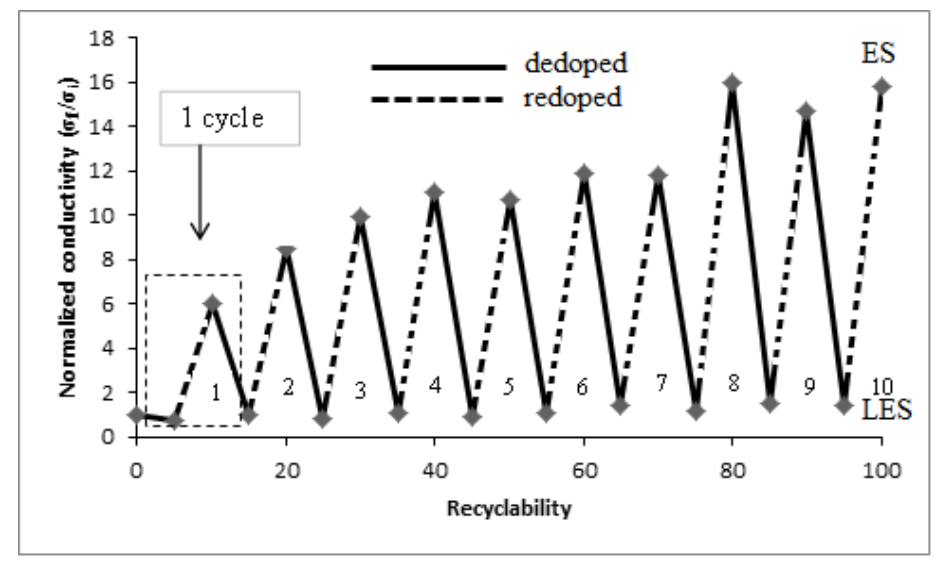

Figure 5. Recyclability of PANI for 100 ppm of hydrazine in terms of conductivity

In this study, for the first time, the UV-Vis and FTIR measurements as the supporting data were used for conductivity study of PANI chemical sensor for hydrazine detection. In the UV-Vis spectra, red-shift can be observed at $\sim 780 \mathrm{~nm}$ due to the interaction of ES with hydrazine to form the LES. In general, ES will possess stretched polaron due to the quinoids as shown in the peak at $780 \mathrm{~nm}$. Once the ES dedoped by hydrazine, the stretched polaron will diminish and shows a red shift which indicates the transformation of ES to LES. In Figure 6, low concentration of hydrazine (10 and $100 \mathrm{ppm}$ ) exhibited shorter wavelength shift while high concentration of hydrazine (1000 and $10000 \mathrm{ppm}$ ) exhibited longer wavelength shift from the initial wavelength of PANI films. This could be explained by the fact that higher concentration of hydrazine will possess higher amount of hydrazinium ions which can readily dedope ES to form the LES compare to the lower concentration of hydrazine which will require more time to interact with ES matrix.

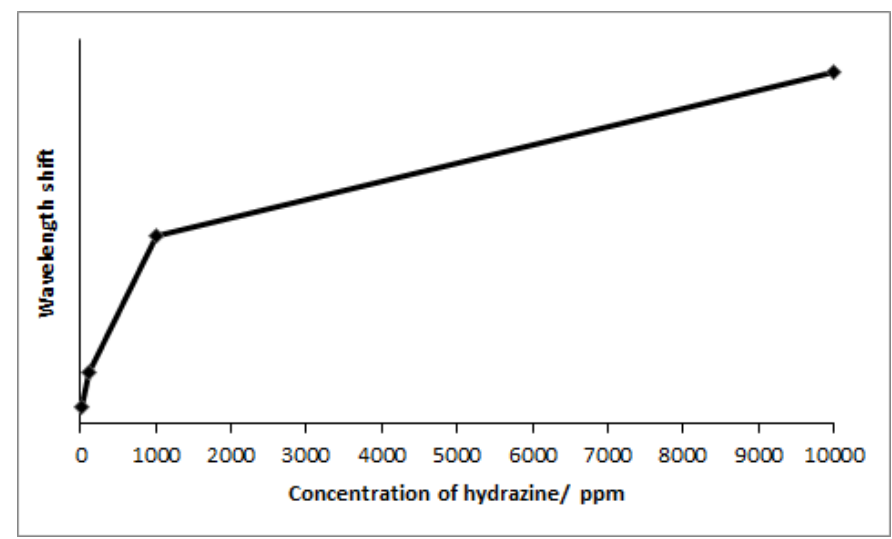

Figure 6. Wavelength shift observed for PANI for different concentration of hydrazine at $780 \mathrm{~nm}$ 
Figure 7 illustrates the supportive data for recyclability of PANI against $100 \mathrm{ppm}$ of hydrazine as explained by the conductivity data from Figure 3. ES exhibit red shift at polaron stretching around $780 \mathrm{~nm}$ upon dedoping by hydrazine which indicates the transformation of ES to LES while blue shift will be observed at polaron stretching when the redoping done by an acid which attributed to the conversion of LES to the conducting state of ES. Thus, Figure 7 clearly confirmed that PANI ES can be recycled up to 10 cycles. This is one of the most important characters of a chemical sensor to be used as a reusable sensor.

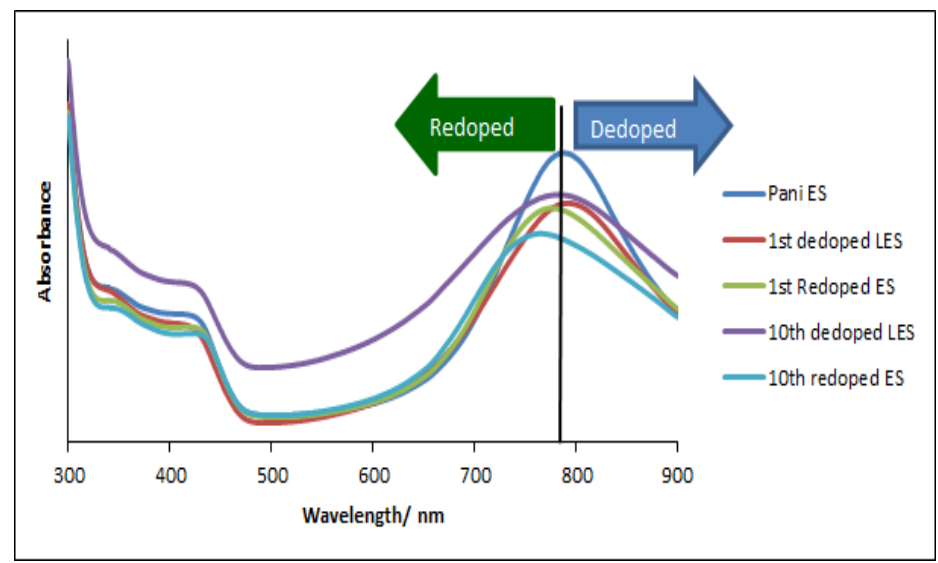

Figure 7. UV-Vis spectra of recyclability of PANI upon dedope by $100 \mathrm{ppm}$ of hydrazine and redope by $1 \mathrm{~N} \mathrm{HCl}$

Figure 8 shows the PANI sensing response against hydrazine by means of FTIR spectra. In general, PANI shows two significant characteristic peaks at 1477 and $1578 \mathrm{~cm}^{-1}$ which corresponds to the benzenoid and quinoid ring stretching, respectively. Thus, the intensity ratio $\left(\mathrm{I}_{1578} / \mathrm{I}_{1477}\right)$ of these bands could be used as an indicator for the degree of oxidation of PANI [27]. Table 1 shows the intensity ratio of ES and LES after exposure to different concentrations of hydrazine. It can be observed that, intensity ratio of LES is smaller than of ES for all hydrazine concentration; this shows that, the presence of benzenoid is predominating in the PANI chain which is an important structure of LES. So, these results further prove the changes of ES to LES upon dedope by hydrazine.

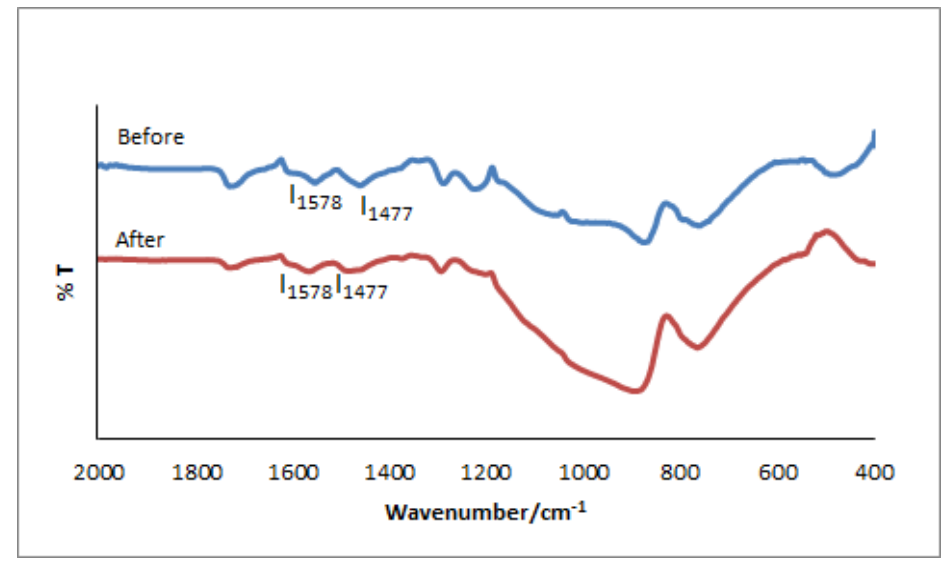

Figure 8. FTIR spectra of PANI before and after exposure with $100 \mathrm{ppm}$ hydrazine 
Table 1. FTIR intensity ratio of quinoid/benzenoid for different concentration of hydrazines

\begin{tabular}{lcc}
\hline $\begin{array}{l}\text { Concentration of Hydrazine } \\
(\mathbf{p p m})\end{array}$ & $\begin{array}{c}\text { ES } \\
\left(\mathbf{I}_{\mathbf{1 5 7 8}} / \mathbf{I}_{\mathbf{1 4 7 7}}\right)\end{array}$ & $\begin{array}{c}\text { LES } \\
\left(\mathbf{I}_{\mathbf{1 5 7 8}} / \mathbf{I}_{\mathbf{1 4 7 7}}\right)\end{array}$ \\
\hline 10 & 1.00 & 0.99 \\
100 & 1.00 & 0.99 \\
1000 & 1.00 & 0.98 \\
10000 & 1.00 & 0.92 \\
\hline
\end{tabular}

\section{Conclusion}

PANI was successfully synthesized and applied as an effective chemical sensor for hydrazine detection. The PANI can detect hydrazine with various concentrations such as $10,100,1000$ and $10000 \mathrm{ppm}$ with recyclability up to 10 cycles. Besides that, PANI sensor measurements were also shown in terms of UV-Vis wavelength shifts and the PANI ES and LES structural changes via FTIR spectra. In future prospect, the PANI sensor study can be carried out in a dynamic range of hydrazine concentration to determine the limit of detection and limit of quantitation. Besides, that incorporation of metal oxides into the PANI matrix would provide synergetic effects for PANI as a chemical sensor.

\section{Acknowledgement}

The authors would like to show high gratitude for the financial support by UiTM Negeri Sembilan Branch, Kuala Pilah Campus to attend SKAM 29 and University of Malaya (UMRG: RP020A-16SUS) for research purposes.

\section{References}

1. Cui, G., Lee, J. S., Kim, S. J., Nam, H., Cha, G. S. and Kim, H. D. (1998). Potentiometric $\mathrm{pCO}_{2}$ sensor using polyaniline-coated pH- sensitive electrodes. Analyst, 123: $1855-1859$.

2. Karyakn, A. A., Lukachona, L. V., Karyakina, E. E., Orlov, A. V. and Kappachora, G.P. (1999). The improved potentiometric $\mathrm{pH}$ response of electrodes modified with processible polyaniline. Application to glucose biosensor. Analytical Communications, 36: 153 - 156.

3. Wu, C. G., Bein, T. (1994), Conducting polyaniline filaments in a mesoporous channel host. Science 264: 1757-1759.

4. Ahmad, N. and MacDiarmid, A. G. (1996). Inhibition of corrosion of steels with the exploitation of conducting polymers. Synthetic Metals, 78: 103 - 110.

5. Rose, T. L., Antonio, S. D., Jilson, M. H., Kron, A.B., Suresh, R. and Wang, F. (1997). A microwave shutter using conductive polymers. Synthetic Metals, 85: 1439 - 1440.

6. MacDiarmid, A. G., (1997). Polyaniline and polypyrrole: Where are we headed? Synthetic Metals, 84: 27 - 34.

7. MacDiarmid, A. G., Chiang, J. C., Halpern, M., Huang, W. S., Mu, S. L., Somasiri, N. L. D., Wu, W. Q. and Yaniger, S. I. (1985). Polyaniline: Interconversion of metallic and insulating forms. Molecular Crystals and Liquid Crystals, 121: $173-180$.

8. Wang, X., Shao, M., Shao, G., Wu, Z. and Wang, S. (2009). A facile route to ultra-long polyaniline nanowires and the fabrication of photoswitch. Journal of Colloid Interface and Science, 332: $74-77$.

9. Koul, S., Dhawan, S. K., Chandra, S. and Chandra, R. (1997). Conducting polyaniline as a sensor for the detection of $\mathrm{HCl}$ vapors. Indian Journal of Chemistry, 36A: $901-904$.

10. Zheng, W., Hu, L., Yoon, L. S. L. and Wong, K.Y. (2016) Copper nanoparticles/polyaniline/graphene composite as highly sensitive electrochemical glucose sensor. Journal of Electroanalytical Chemistry, 781: 155 -160 .

11. Umar, A., Rahman M. M., Kim, S. H. and Han, Y. B. (2008). Zinc oxide nanonail based chemical sensor for hydrazine detection. Chemical Communication, 2: $166-168$.

12. Golabi, S. M. and Zare, H. R. (1999). Electrocatalytic oxidation of hydrazine at a chlorogenic acid (CGA) modified glassy carbon electrode. Journal of Electroanalytical Chemistry, 465: 168 - 176.

13. Omar, F. S., Numan, A., Duraisamy, N. and Bashir, S. (2017). A promising binary nanocomposite of zinc cobaltite intercalated with polyaniline for supercapacitor and hydrazine sensor. Journal of Alloys and Compounds, 716: $96-105$. 
14. Umar, A., Abaker, M., Faisal, M., Hwang, S. W., Baskoutas, S. and Al-Sayari, S. A. (2011). High-yield synthesis of well crystalline $\alpha-\mathrm{Fe}_{2} \mathrm{O}_{3}$ nanoparticles: Structural, optical and photocatalytic properties. Journal of Nanoscience and Nanotechnology, 11:3474-3480.

15. Ibrahim, A. A., Dar, G. N., Zaidi, S. A., Umar, A., Abaker, M., Bouzid, H. and Baskouts, S. (2012). Growth and properties of Ag-doped $\mathrm{ZnO}$ nanoflowers for highly sensitive phenyl hydrazine chemical sensor application. Talanta, 93: $257-263$.

16. Ravichandran, K. and Baldwin, R. P. (1983), Liquid chromatographic determination of hydrazines with electrochemically pretreated glassy carbon electrodes. Analytical Chemistry, 55: $1782-1786$.

17. Kamyabi, M. A., Shahabi, S., Hosseini, M. H. (2008), Electrocatalytic oxidation of hydrazine at a cobalt (II) Schiff-base-modified carbon paste electrode. Journal of Electrochemical Society, 155: 8 - 12.

18. Maleki, N., Safavi, A. and Tajabadi, F. (2008). Palladium nanoparticle decorated carbon ionic liquid electrode for highly efficient electrocatalytic oxidation and determination of hydrazine. Analytica Chimica Acta, 611: 151 -155 .

19. Nassef, H. M., Radi, A. E. and O'Sullivan, C. K. (2006). Electrocatalytic oxidation of hydrazine at oaminophenol grafted modified glassy carbon electrode: Reusable hydrazine amperometric sensor. Journal of Electroanalytical Chemistry, 592: 139 - 146.

20. Zare, H. R. and Nasirizadeh, N. (2007), Hematoxylin multi-wall carbon nanotubes modified glassy carbon electrode for electrocatalytic oxidation of hydrazine. Electrochimica Acta, 52: 4153 - 4160.

21. Zheng, L. and Song, J. F. (2009). Curcumin multi-walled carbon nantubes modiefied galssy carbon electrode and its electrocatalytic activity towards oxidation of hydrazine. Sensors and Actuators B-Chemical, 135: 650 655 .

22. Koul, S., Chandra, R. and Dhawan, S. K. (2001). Conducting polyaniline composite: a reusable sensor material for aqueous ammonia. Sensors and Actuators B-Chemical, 75: $151-159$.

23. Tai, H., Jiang, Y., Xie, G. and Yu, J. (2010). Preparation, characterization and comparative NH3-sensing characteristic studies of PANI/inorganic oxides nanocomposite thin film. Journal of Materials Science and Technology, 26: $605-613$.

24. Runge, M. B., Dadsetan, M., Baltrusaitis, J., Knight, A. M., Ruesink, T., Lazcano, E. A., Lu, L., Windebank, A. J. and Yaszemski, M. J. (2010). The development of electrically conductive polycaprolactone fumaratepolypyrrole composite materials for nerve regeneration. Biomaterials, 31: 5916 - 5926.

25. Virji, S., Kaner, R. B. and Weiller, B. H. (2005). Hydrazine detection by polyaniline using fluorinated alcohol additives. Chemistry of Materials, 17: 1256 - 1260.

26. Xing, S., Zhao, C., Jing, S., Wu, Y. and Wang, Z. (2006). Morphology and gas sensing behavior of in situ polymerized nanostructured polyaniline films. European Polymer Journal, 42: 2730 - 2735.

27. Choi, B. G., Park, H. S., Im, H. S. and Kim, Y. J. (2008). Influence of oxidation state of polyaniline on physicochemical and transport properties of Nafion/polyaniline composite membrane for DMFC. Journal of Membrane Science, 324: 102 - 107. 